\title{
A Review on the Faults of Electric Machines Used in Electric Ships
}

\author{
Dionysios V. Spyropoulos and Epaminondas D. Mitronikas \\ Electromechanical Energy Conversion Laboratory, Department of Electrical and Computer Engineering, \\ University of Patras, 26504 Rio, Patras, Greece \\ Correspondence should be addressed to Dionysios V. Spyropoulos; dionspyrop@ece.upatras.gr
}

Received 25 October 2012; Revised 6 February 2013; Accepted 6 February 2013

Academic Editor: George Antonopoulos

Copyright (C) 2013 D. V. Spyropoulos and E. D. Mitronikas. This is an open access article distributed under the Creative Commons Attribution License, which permits unrestricted use, distribution, and reproduction in any medium, provided the original work is properly cited.

Electric propulsion systems are today widely applied in modern ships, including transport ships and warships. The ship of the future will be fully electric, and not only its propulsion system but also all the other services will depend on electric power. The robust and reliable operation of the ship's power system is essential. In this work, a review on the mechanical and electrical faults of electric machines that are used in electric ships is presented.

\section{Introduction}

The idea to use electric power for the propulsion of ships is not new, as from the beginning of the twentieth century electric ship propulsion systems had shown advantages compared to the traditional ones using internal combustion engines. Since the 1980s, there has been an explosion in the number and variety of electrical propelled ships built around the world, from cruise liners to warships. Since the beginning of the last century, both AC and DC propulsion systems have been used. Moreover, the great evolution in the field of power electronics offered the means for efficient AC machines control, even in the case of high-power machines like those used in ship propulsion systems [1]. The ship of the future will be fully electric, as not only concerning its propulsion system but also all the other vital functions like navigation, and ship services will depend on electric power. To achieve this goal, the integrated power and propulsion system has to be designed properly in order to be robust, to achieve uninterrupted operation, to be fault tolerant, and able to continue its operation in case of failure through reconfiguration. Thus, timely hardware and electric propulsion machine diagnostics play a crucial role in maintaining the trouble-free operation of the ship.

The "heart" of the ship's integrated power system is the electric machine. The widespread application of electric machines for power generation, propulsion, thermal management systems, and so forth, makes their robust and reliable operation a crucial aspect. Usually, induction motors and permanent magnet motors are used in ship propulsion systems with high power ratings.

In this paper, the most common electrical and mechanical faults of these machines are presented.

\section{Modern Electric Ship Propulsion System}

The vast majority of ships are propelled directly from fossil fuel powered engines using mechanical transmission and gearboxes, as shown in Figure 1. The electrical part of such a system achieves $95 \%$ efficiency in nominal operation. Nowadays, an increasing number of ship propulsion systems manufacturers consider developing electric propulsion systems for commercial and cargo ships, while respective programs are under development for adopting electric propulsion in warships [2-4]. In such propulsion systems, generators convert prime mover rotational power into electric power, which is transmitted in electric propulsion motors in order to produce the necessary rotational power, as shown in Figure 2. Electric propulsion systems offer many advantages in terms of fuel economy, maneuverability, performance, and reduced manpower $[5,6]$. 


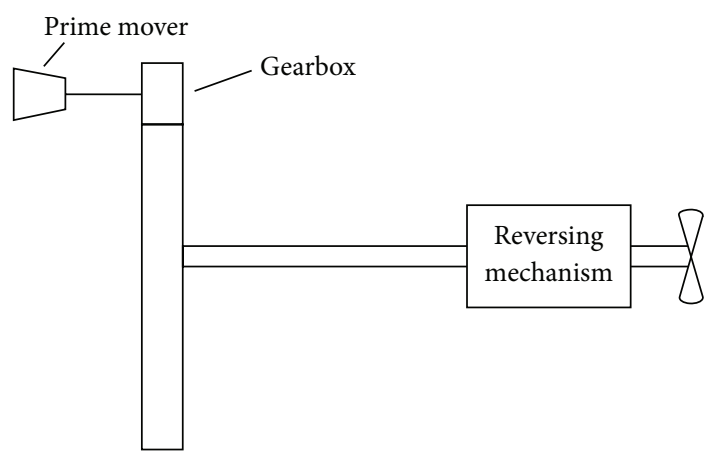

FIgURE 1: Propulsion system with mechanical transmission [5].

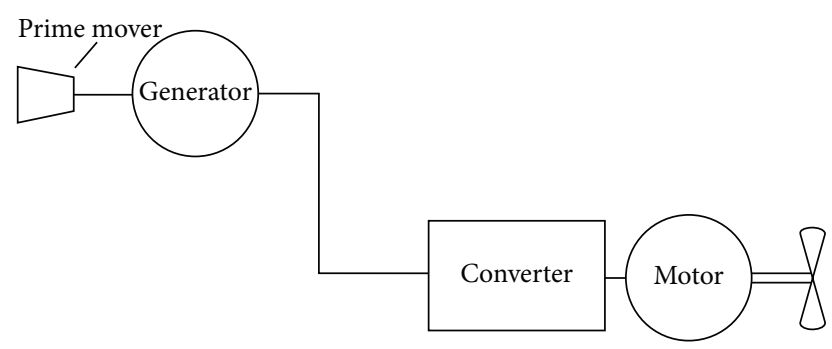

Figure 2: Propulsion system in an electric ship [5].

As it has been already noted, the ship of the future will be fully electric (All Electric Ship). The integrated system of this kind of ship will use powerful electric machines driven by advanced power electronic devices which will be controlled by sophisticated software [6]. The total needs for propulsion, navigation, and other services like ventilation systems, refrigeration plants, pumps, cranes, hoists, winches, and so forth, have to be covered by the produced electric power. Such a system is shown in Figure 3. Moreover, in the case of warships, the presence of more electric power demanding equipment (e.g., weapon systems) means that more installed power and reliability are required.

Taking into consideration that the fully electric ship is rather a novel technology approach, it has to be designed taking advantage of the already mature industrial technology concerning drives, control, and hardware diagnostics.

More specifically, hardware and electric machine diagnostics will play an important role in maintaining the continuous and reliable operation of the ship.

From the viewpoint of the engineer, the accuracy of the embedded diagnostic systems is essential in order to implement reconfigurable control algorithms in case of fault, thus achieving the ship's uninterrupted operation and survivability. As far as maintenance is concerned, high-level diagnostic accuracy is important for the isolation and quick repair of the fault and moreover for the more effective scheduling of preventive maintenance [8]. The most important part of the ship's integrated power system is undoubtedly the electric machines that are used. Particularly for the high-power electrical machines, the replacement procedure in case of fault can reach up to very high costs, while onboard replacement of a faulty unit is impossible. Consequently, their robust design and continuous condition monitoring are crucial in order to timely diagnose and repair any fault before it may lead to the complete failure of the system.

\section{Electric Machines and Fault Diagnosis}

3.1. Overview. The types of electric propulsion and supplemental motors usually used nowadays in ships are induction (asynchronous) motors, synchronous motors, and permanently excited synchronous motors (permanent magnet motors).

Induction motors (IMs) are currently the most widespread motors. This is due to their low cost, simple manufacturing, reliability, and robustness, while their efficiency is up to $96 \%$.

Permanent magnet (PM) motors have similar stator construction as the induction machines, but the conventional rotor is replaced by an arrangement of permanent magnets, thus achieving higher torque density and relatively improved efficiency (up to 98\%).

Finally, synchronous motors achieve fairly high efficiency (about 97\%), requiring, though, a DC excitation source (in the rotor).

As already noted, electrical machines and drives have very low maintenance requirements; however, the ship's challenging operating environment makes them more vulnerable to failures. For this reason, many machines used in ship installations include specific resistors for reducing the wetness whereas for preventing problems caused by ship vibrations these are mounted on special bases. In any case, if a severe fault occurs it is extremely difficult to repair it onboard while any loss of electric propulsion power onboard would have devastating consequences. Thus, it is essential to diagnose the fault at its very early stages so that the maintenance procedure can be programmed before the fault leads to catastrophic events.

The main faults in the aforementioned electric machines can be classified as [9-15]:

(i) stator faults resulting in the open or short circuits on one or more stator windings;

(ii) broken rotor bar or end-ring faults on induction motors;

(iii) static or/and dynamic air-gap irregularities (rotor eccentricity);

(iv) bearing and gearbox failures;

(v) short circuit in the rotor field windings;

(vi) defects of the permanent magnets of PM motors.

Each fault disturbs the motor's normal operation producing several symptoms, like unbalanced line currents and air-gap voltages, torque and speed pulsations, decreased efficiency and average torque, excessive heating, and increased losses.

Through the industrial experience several surveys of faults of electrical machines have been conducted. In Table 1 [11], the results of the surveys of IEEE-IAS, ERPI, and Allianz are compared concerning Induction machines. 


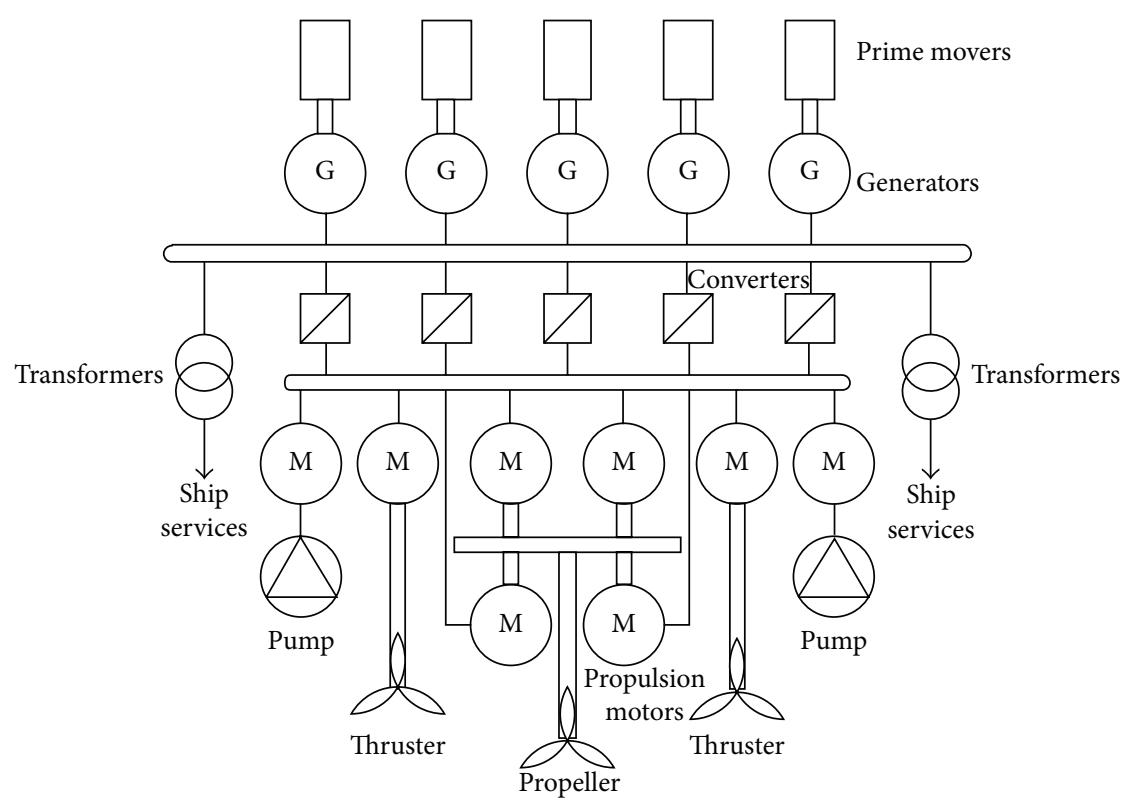

Figure 3: "All Electric Ship" power system topology [7].

TABLE 1: Comparison of IEEE-IAS, ERPI, and Allianz surveys.

\begin{tabular}{lccc}
\hline $\begin{array}{l}\text { Major } \\
\text { components }\end{array}$ & $\begin{array}{c}\text { IEEE-IAS \% } \\
\text { of failures }\end{array}$ & $\begin{array}{c}\text { ERPI \% of } \\
\text { failures }\end{array}$ & $\begin{array}{c}\text { Allianz \% of } \\
\text { failures }\end{array}$ \\
\hline Bearing related & 44 & 41 & 13 \\
Stator related & 26 & 36 & 66 \\
Rotor related & 8 & 9 & 13 \\
Other & 22 & 14 & 8 \\
\hline
\end{tabular}

The Allianz survey focuses on medium- to high-voltage large induction machines like these that are used in electric ships and it is clear that stator-related faults are the most prominent for high-power machines. Moreover, in [16] a survey that focuses on electric motors used in offshore applications shows that the main faults are also due to bearing and stator winding defects. In [17], several real cases of faults in high-power electric machines are presented, analyzing thoroughly the causes (e.g., pages 45, 51, and 58.).

Traditionally, monitoring the line currents and analyzing them using several signal processing methods (FFT, Wavelets, Park's vector approach, etc.) $[10,15]$, one can reliably diagnose the existence and severity of the fault. The motor current signature analysis (MCSA) is broadly used, as it is a reliable and nonintrusive method, while for the monitoring, current sensors already incorporated in the drive system can be effectively used. In MCSA, the spectrum of the machine's line currents is investigated, in order to detect a fault. Several characteristic frequencies of the current identify the presence or not of each fault, while their amplitudes determine the fault's severity. Alternatively, instantaneous power and torque monitoring, temperature monitoring, acoustic methods, vibration signal analysis, and zero or negative sequence voltage monitoring have also been proposed; however, while the MCSA is the less intrusive for the system method, it is the most used one providing reliable results [9-14].

In the following paragraphs a more detailed approach for each electrical and mechanical fault in IM and PM machines is presented while the characteristic current frequencies which indicate each fault using the MCSA technique are given.

3.2. Stator Faults in AC Machines. The stator windings of medium- and high-voltage AC machines are normally formwound coils. Induction and synchronous permanent magnet machines have the same stator structure. Their insulation is based on advanced materials compared to small induction machines and its constant monitoring is essential, given that any fault will lead to catastrophic results. Usually insulation defects are the result of long-term aging or contamination mainly because of the very high operating temperature. While the major failure contributors are abnormal moisture, poor ventilation, high vibration, abnormal voltage, and persistent overloading [16], an insulation failure, typically, takes less than $30 \mathrm{~s}$ to expand and finally leads to the destruction of the stator core [9-14, 18-21].

The existence of a stator fault could be detected using the line currents of the machine. Under ideal conditions, the current Park vector components $\left(I_{d}, I_{q}\right)$ are calculated in terms of mains phase variables $\left(I_{a}, I_{b}, I_{c}\right)$ as [19-21]:

$$
\begin{gathered}
I_{d}=\sqrt{\frac{2}{3}} I_{a}-\sqrt{\frac{1}{6}} I_{b}-\sqrt{\frac{1}{6}} I_{c}, \\
I_{q}=\sqrt{\frac{1}{2}} I_{b}-\sqrt{\frac{1}{2}} I_{c} .
\end{gathered}
$$


Under ideal conditions, the 3-phase currents lead to a Park's vector with the following components:

$$
\begin{gathered}
I_{d}=\frac{\sqrt{6}}{2} I_{M} \sin (\omega t), \\
I_{q}=\frac{\sqrt{6}}{2} I_{M} \sin \left(\omega t-\frac{\pi}{2}\right),
\end{gathered}
$$

where $I_{M}$ is the peak value of motor phase current and $\omega$ is the angular frequency. The space vector magnitude is given as follows:

$$
M g=\left|\sqrt{I_{d}^{2}+I_{q}^{2}}\right|
$$

The corresponding representation of (3) is a circular locus centered at the origin of the coordinates, as shown in Figure 4.

Under a fault condition, the three-phase currents will carry additional components leading to a different representation of the Park's vector, as shown in Figure 5. The change of the pattern of the Park's vector, in addition to the presence of an AC component at twice the supply frequency $2 f_{s}$, is an indicator of the stator fault.

\subsection{Broken Rotor Bar/End-Ring Failures of Asynchronous} Motors. Asynchronous Cage Motors are divided into two categories, depending on the construction of the cage, cast and fabricated. The material used for cast cage is aluminum, whereas for fabricated is copper. For high-power motors, fabricated cage rotors are used. Broken bar faults are caused by a variety of reasons: thermal, mechanical, magnetic, residual, dynamic, and environmental stresses [9-14]. These stresses originate from human, manufacturing, and functioning errors causing asymmetry to the geometry of the machine and consequently inducing asymmetrical spatial strain. The currents in a healthy rotor are presented in Figure 6. Under faulty conditions (broken bar/end-ring fault), the amplitude of the current changes in the area of the fault, as shown in Figure 7 [22].

Upon the occurrence of this type of fault, the characteristic frequency of the supply current that occurs is [9-14, 2225]:

$$
f_{\text {brb }}=(1 \pm 2 k s) f_{s}, \quad k=1,2,3, \ldots,
$$

where $f_{s}$ is the supply frequency, $k$ is an integer order number, and $s$ is the slip. As the fault severity increases, the amplitudes also increase considerably.

3.4. Bearing Faults. Bearing faults are very common in both low- and high-voltage electric motors and special attention is required. Almost $40 \%-50 \%$ of all motors' failures are bearing related. For high-power motors, both rolling ball and sleeve bearing are used. The major causes for bearing failures are the thermal, mechanical, and electrical stresses, contamination and corrosion, improper installation, and improper lubrication. It is generally believed that bearing failures develop from general roughness and gradually lead to defect of the bearing components [9-13, 16, 26, 27]. Bearings

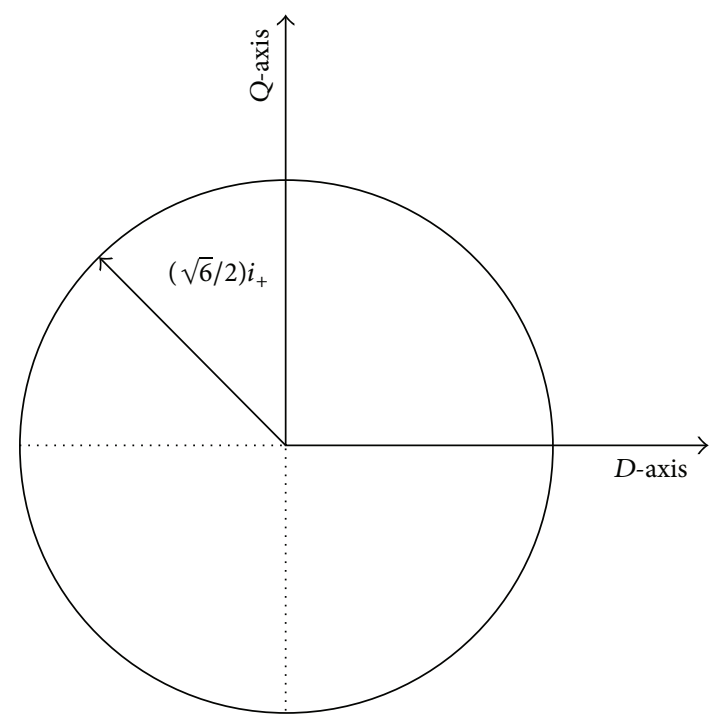

FIgURE 4: The current Park vector representation under ideal conditions.

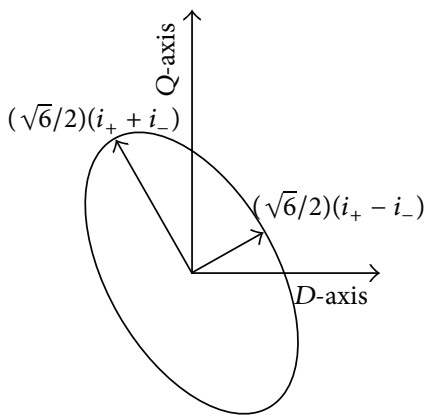

(a)

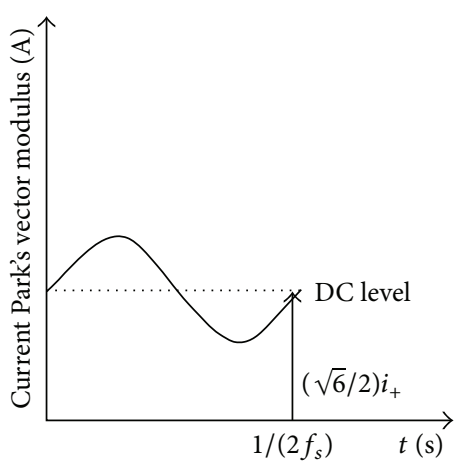

(b)

FIgure 5: (a) Current Park's vector representation under abnormal conditions and (b) current Park's vector modulus under abnormal conditions.

faults condition monitoring is important for asynchronous and permanent magnet machines that are used in the electric ship, while any bearing defection will cause speed and torque pulsations, thus reducing the efficiency of the machine. 


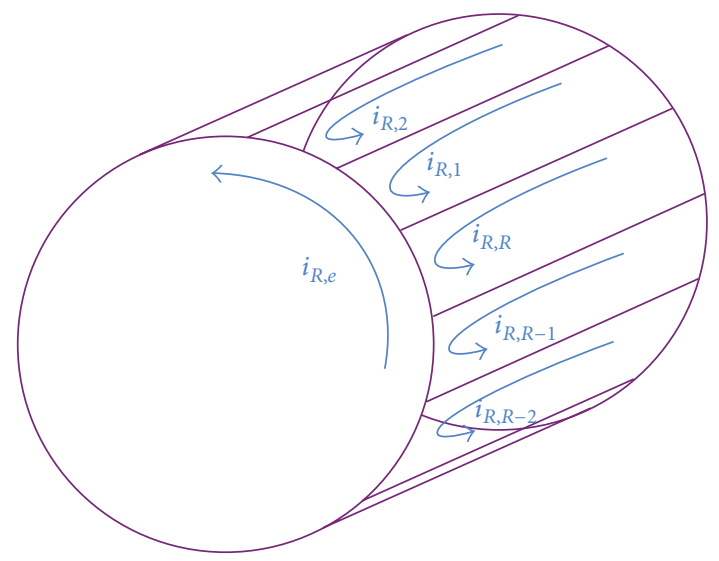

(a)

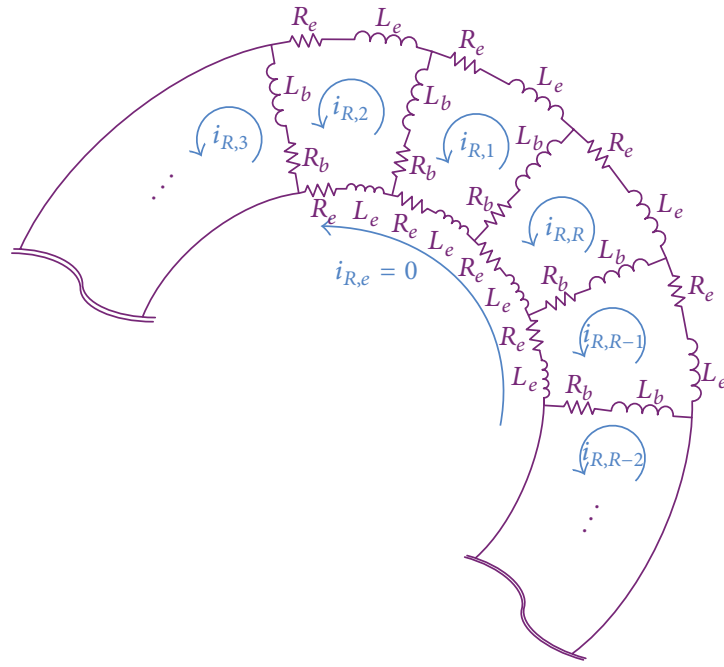

(b)

FIGURE 6: (a) Sketch of the rotor of a healthy squirrel cage asynchronous machine. (b) Equivalent circuit of the rotor of a healthy squirrel cage asynchronous machine [22].

The diagnosis of the bearing failure can also be done through the examination of the current spectrum, the characteristic frequencies are given as follows $[9-13,27]$ :

$$
f_{\text {bng }}=\left|f_{s} \pm k f_{u}\right| \text {, }
$$

where $f_{s}$ is the supply frequency, $k$ is an integer order number, and $f_{u}$ is a characteristic vibration frequency strongly connected to the geometry of the bearings as shown in [9].

3.5. Eccentricity-Related Faults. Machine eccentricity is the condition where unequal air gap exists between the rotor and the stator. If the degree of the eccentricity becomes large, the resulting unbalanced radial forces may cause rub between the stator and the rotor leading to the destruction of the machine. There are two kinds of eccentricity: static eccentricity and dynamic eccentricity, as presented in Figure 8, where the arrows indicate the misalignment between the rotor center and the rotational center at each case. In the case of the static air gap eccentricity, the position of the minimum radial air gap length is fixed in space. On the other hand, in the case of the dynamic eccentricity the center of the rotor does not coincide with the center of rotation, thus the position of the minimum air gap rotates with the rotor. The main causes of static eccentricity are the ovality of the stator core or the incorrect positioning of the stator or the rotor at the commissioning stage. However, dynamic eccentricity may be caused by a bent rotor shaft, misalignment or wear of the bearings, mechanical resonance at a critical speed, and so forth.

It should be noted that a degree of eccentricity at around $10 \%$ is generally admissible. However, machine manufacturers keep the total level of eccentricity even lower in order to reduce vibration and noise [9].
Investigating the current spectrum, eccentricity-faultrelated harmonics are given as follows [9-13]:

$$
f_{\mathrm{ecc}}=f_{s}\left[\left(n R \pm n_{d}\right)\left(\frac{(1-s)}{p}\right) \pm n_{\mathrm{ws}}\right],
$$

where $n_{d}=0$ in the case of static eccentricity, $f_{s}$ is the supply frequency, $R$ is the number of rotor slots, $s$ is the slip, $p$ is the number of pole pairs, $n$ is a positive integer, and $n_{\mathrm{ws}}$ is the order of the stator time harmonics that are present in the power supply driving the motor.

Usually, in practical cases there is a combination of static and dynamic eccentricity, and the frequency harmonics that indicate the fault are given as follows:

$$
f_{\text {ecc }}=f_{s}\left(1 \pm \frac{(1-s)}{p}\right) .
$$

Moreover, in [28] the diagnosis of dynamic eccentricity fault in PM motors is achieved investigating the current harmonics given by

$$
f_{\mathrm{ecc}}=f_{s}\left(1 \pm \frac{(2 k-1)}{p}\right),
$$

where $k$ is an integer.

3.6. Rotor Magnets Defects in Permanent Magnet Motors. Monitoring the magnet status of PM motors is very important since local or uniform demagnetization caused by operating stresses lead to irreversible degradation of motor efficiency. Defects leading to demagnetization or disintegration of permanent magnets are caused by thermal, mechanical, or environmental stresses $[5,29]$.

Investigating the current spectrum, permanent magnetfault-related harmonics are given as follows [29]:

$$
f_{\mathrm{dm}}=f_{s}\left(1 \pm \frac{k}{p}\right) \text {, }
$$




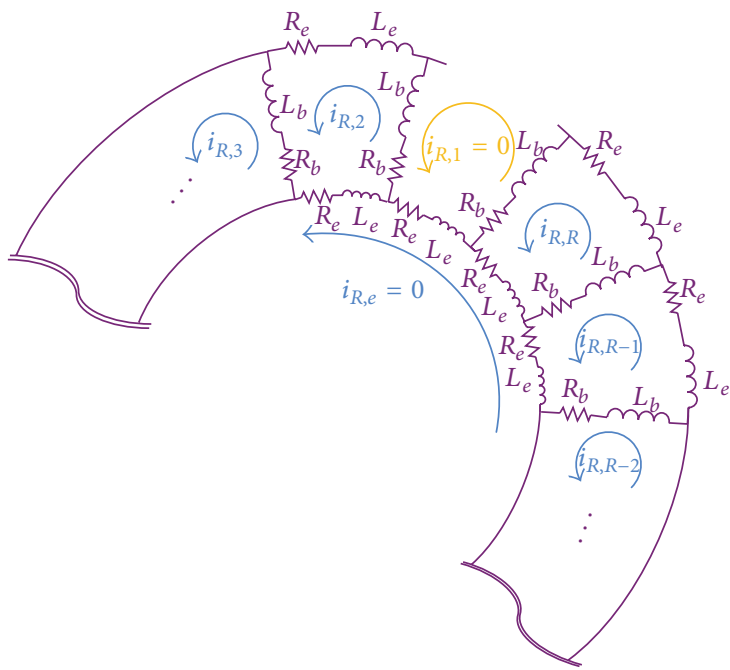

(a)

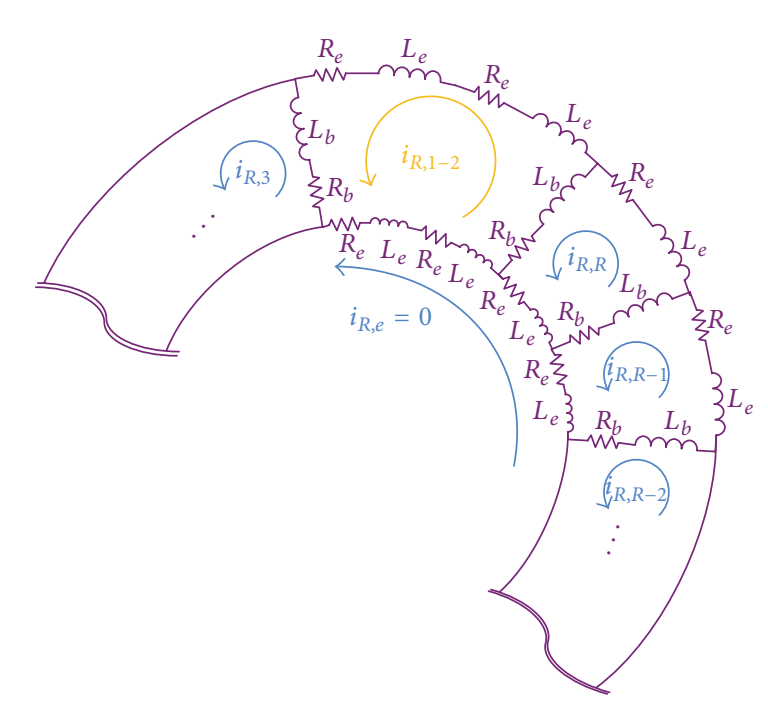

(c)

FIGURE 7: (a), (b) Equivalent circuit of the rotor of a squirrel cage asynchronous machine under end-ring fault. (c) Equivalent circuit of the rotor of a squirrel cage asynchronous machine under broken bar fault [22].

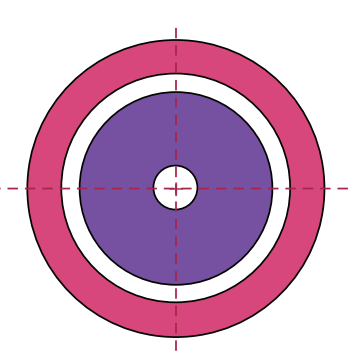

(a)

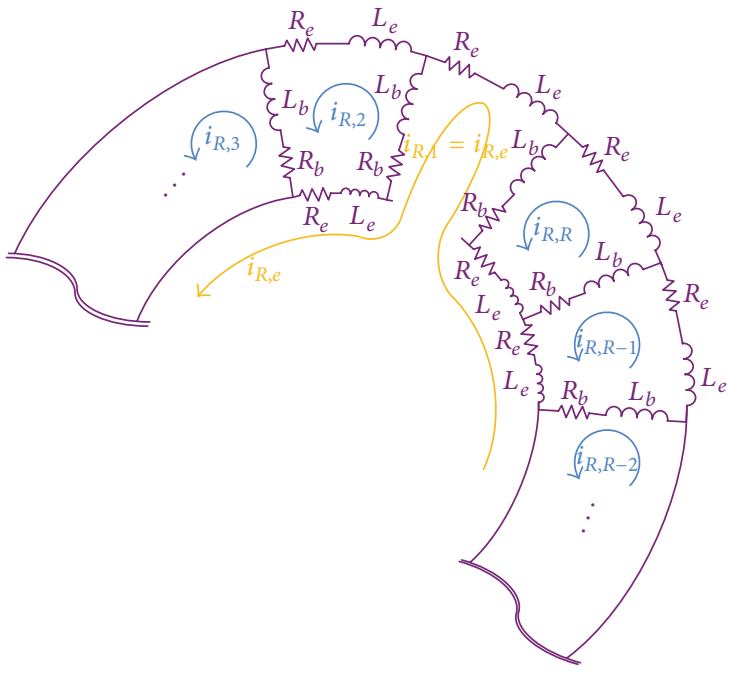

(b)

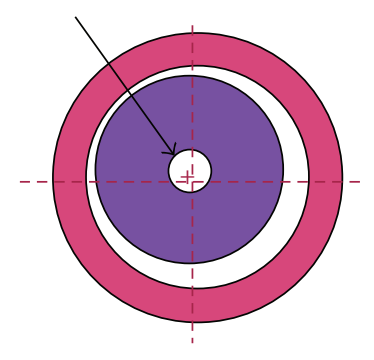

(b)

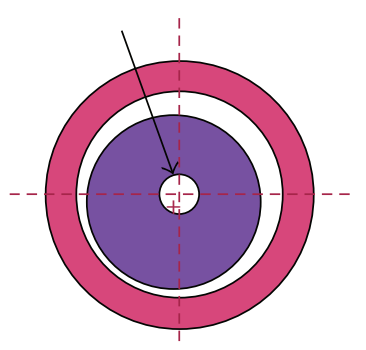

(c)

FIGURE 8: Sketch of the rotor of an induction machine: (a) healthy case, (b) under static eccentricity, and (c) under dynamic eccentricity [22]. 
where $f_{s}$ is the supply frequency, $p$ the number of pole pairs, and $k$ is a positive integer.

\section{Conclusions}

In this paper, a review of electrical and mechanical faults of asynchronous and permanents magnet machines is presented. Moreover, for each type of fault, the characteristic frequencies of the current spectrum that indicate the presence and severity of the failure are given. In the literature, it has also been proposed that other signals can be used for the fault diagnosis, like the torque, the power, the supply voltages, and the motor speed. Using a combination of these signals and the appropriate signal processing techniques, the engineer can extract accurate information about the condition of the machine. The field of condition monitoring, fault diagnosis, and fault prognosis is of great research interest; the last years and novel frequency ranges are investigated as fault indicators while state-of-the-art signal processing techniques are applied for the online condition monitoring of the machines under varying operating conditions.

\section{References}

[1] T. J. McCoy, “Trends in ship electric propulsion," in Proceedings of the IEEE Power Engineering Society Summer Meeting, pp. 343346, July 2002.

[2] The Frontrunner, "A new era in ship propulsion: The first large size (154K) LNG carrier with electric propulsion is now in operation," ABB Marine, March 2007.

[3] Rolls Royce, "New electric hybrid propulsion system," http:// www.rolls-royce.com/Images/hsg_brochure_tcm92-26884.pdf.

[4] VEM-GROUP, http://www.vem-group.com/fileadmin/content/pdf/Produkte_Komponente/Mittel_und_Hochspannung/Schiffbau/schiffbau_0908_e.pdf.

[5] C. G. Hodge and D. J. Mattick, "The electric warship," Transactions of Institute of Marine Engineers, vol. 108, pp. 109-125.

[6] E. D. Mitronikas and E. C. Tatakis, "Migrating the experience of industrial systems to electric ships: propulsion motors and fault detection," in Proceedings of the 1st Marinlive International Workshop on Electric Machines and Power Converters, 2012.

[7] S. A. Gertsos, J. M. Prousalidis, and C. A. Frangopoulos, "Electric Propulsion: from Infancy to adolensense," in Proceedings of the 8th International Marine Design Conference, Athens, Greece, May 2003.

[8] K. P. Logan, "Intelligent diagnostic requirements of future allelectric ship integrated power system," IEEE Transactions on Industry Applications, vol. 43, no. 1, pp. 139-149, 2007.

[9] S. Nandi, H. A. Toliyat, and X. Li, "Condition monitoring and fault diagnosis of electrical motors-a review," IEEE Transactions on Energy Conversion, vol. 20, no. 4, pp. 719-729, 2005.

[10] M. E. H. Benbouzid and G. B. Kliman, "What stator current processing-based technique to use for induction motor rotor faults diagnosis?" IEEE Transactions on Energy Conversion, vol. 18, no. 2, pp. 238-244, 2003.

[11] P. Zhang, Y. Du, T. G. Habetler, and B. Lu, "A survey of condition monitoring and protection methods for medium-voltage induction motors," IEEE Transactions on Industry Applications, vol. 47, no. 1, pp. 34-46, 2011.
[12] M. E. H. Benbouzid, "A review of induction motors signature analysis as a medium for faults detection," IEEE Transactions on Industrial Electronics, vol. 47, no. 5, pp. 984-993, 2000.

[13] A. M. Trzynadlowski and E. Ritchie, "Comparative investigation of diagnostic media for induction motors: a case of rotor cage faults," IEEE Transactions on Industrial Electronics, vol. 47, no. 5, pp. 1092-1099, 2000.

[14] G. S. Khalaf and A. F. Mohamed Haider, "Diagnosis and fault tolerant control of the Induction motors techniques a review," Australian Journal of Basic and Applied Sciences, vol. 4, no. 2, pp. 227-246, 2010.

[15] S. H. Kia, H. Henao, and G. A. Capolino, "Digital signal processing for induction machines diagnosis-a review," in Proceedings of the 33rd Annual Conference of the IEEE Industrial Electronics Society (IECON '07), pp. 1155-1162, November 2007.

[16] O. V. Thorsen and M. Dalva, "Survey of faults on induction motors in offshore oil industry, petrochemical industry, gas terminals, and oil refineries," IEEE Transactions on Industry Applications, vol. 31, no. 5, pp. 1186-1196, 1995.

[17] P. Tavner, L. Ran, J. Penman, and H. Sedding, Condition Monitoring of Rotating Electrical Machines, IET Power and Energy Series, IET, 2008.

[18] A. Stavrou, H. Sedding, and J. Penman, "Current monitoring for detecting inter-turn short circuits in induction motors," in Proceedings of the IEEE International Electric Machines and Drives Conference, pp. 345-347, 1999.

[19] S. M. A. Cruz and A. J. Marques Cardoso, "Stator winding fault diagnosis in three-phase synchronous and asynchronous motors, by the extended park's vector approach," IEEE Transactions on Industry Applications, vol. 37, no. 5, pp. 1227-1233, 2001.

[20] I. Jaksch and P. Fuchs, "Using space transformation for exact diagnostic of induction motor stator faults," in Proceedings of the International Symposium on Diagnostics of Electric Machines, Power Electronics, and Drives (SDEMPED '05), Vienna, Austria, September 2005.

[21] D. V. Spyropoulos and E. D. Mitronikas, "Induction motor stator fault diagnosis technique using Park vector approach and complex wavelets," in Proceedings of the 20th International Conference on Electrical Machines (ICEM '12), pp. 1730-1734, 2012.

[22] I. P. Georgakopoulos, Development of fault diagnosis methods in controlled motor systems composed by electronic power converters and asynchronous machine [Ph.D. thesis], University of Patras, Patras, Greece, 2010.

[23] J. Milimonfared, H. M. Kelk, S. Nandi, A. D. Minassians, and H. A. Toliyat, "A novel approach for broken-rotor-bar detection in cage induction motors," IEEE Transactions on Industry Applications, vol. 35, no. 5, pp. 1000-1006, 1999.

[24] I. P. Tsoumas, G. Georgoulas, E. D. Mitronikas, and A. N. Safacas, "Asynchronous machine rotor fault diagnosis technique using complex wavelets," IEEE Transactions on Energy Conversion, vol. 23, no. 2, pp. 444-459, 2008.

[25] H. Henao, H. Razik, and G. Capolino, "Analytical approach of the stator current frequency harmonics computation for detection of induction machine rotor faults," IEEE Transactions on Industry Applications, vol. 41, no. 3, pp. 801-807, 2005.

[26] W. Zhou, T. G. Habetler, and R. G. Harley, "Bearing condition monitoring methods for electric machines: a general review," in Proceedings of the IEEE International Symposium on Diagnostics for Electric Machines, Power Electronics and Drives (SDEMPED '07), pp. 3-6, September 2007.

[27] M. J. Devaney and L. Eren, "Detecting motor bearing faults: monitoring an induction motor's current and detecting bearing 
failure," IEEE Instrumentation and Measurement Magazine, vol. 7, no. 4, pp. 30-50, 2004.

[28] B. M. Ebrahimi, J. Faiz, and M. J. Roshtkhari, "Static-, dynamic, and mixed-eccentricity fault diagnoses in permanent-magnet synchronous motors," IEEE Transactions on Industrial Electronics, vol. 56, no. 11, pp. 4727-4739, 2009.

[29] D. Casadei, F. Filippetti, C. Rossi, and A. Stefani, "Magnets faults characterization for permanent magnet synchronous motors," in Proceedings of the IEEE International Symposium on Diagnostics for Electric Machines, Power Electronics and Drives (SDEMPED '09), September 2009. 

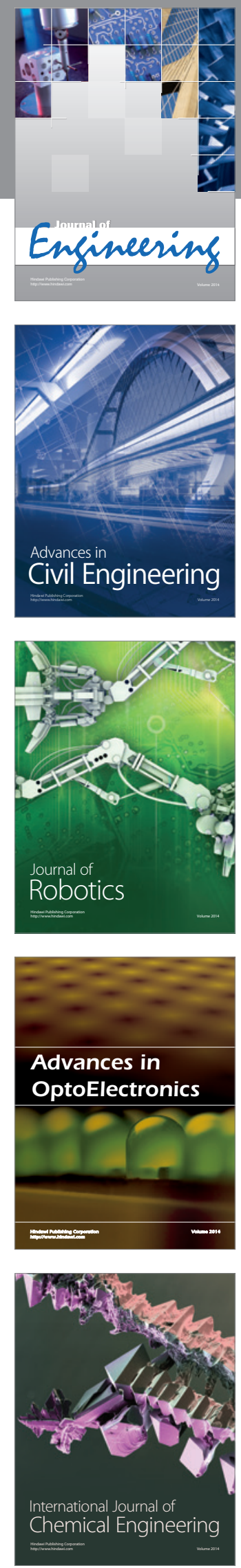

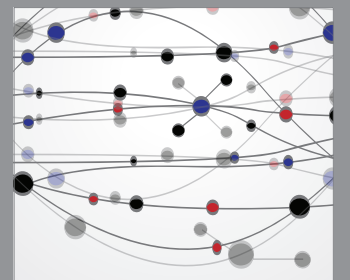

The Scientific World Journal
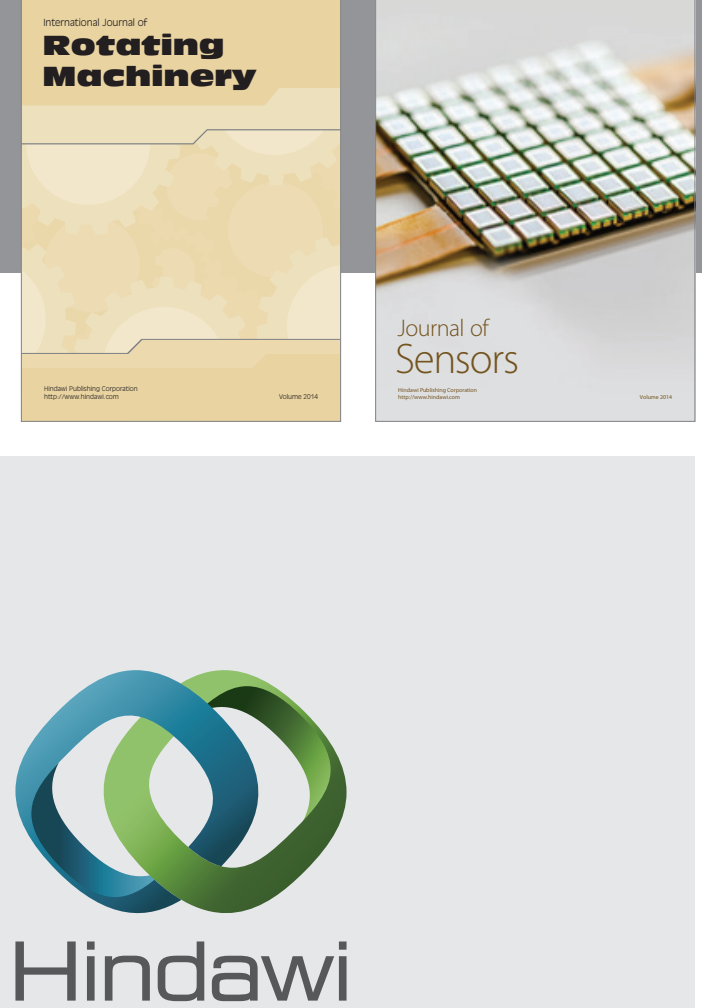

Submit your manuscripts at http://www.hindawi.com
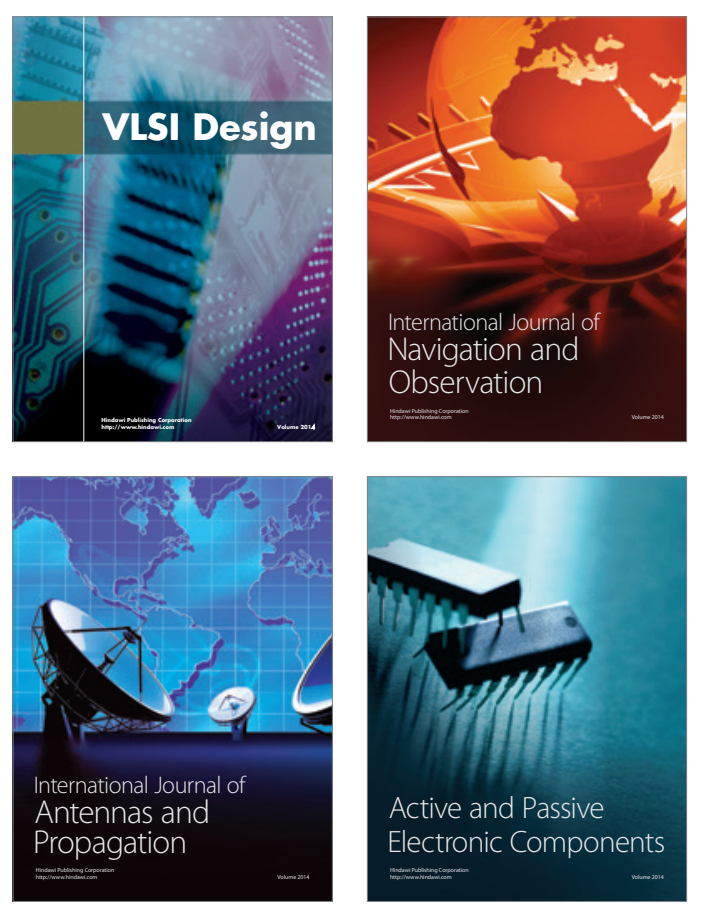
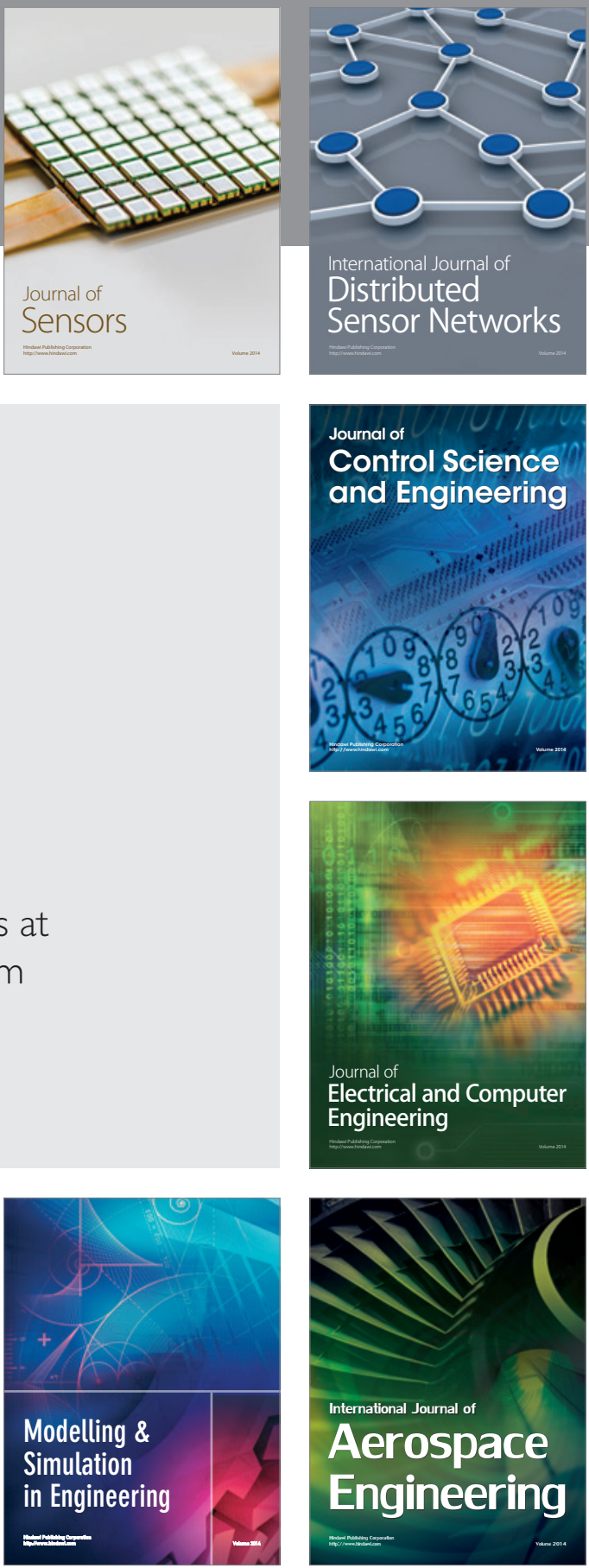

Journal of

Control Science

and Engineering
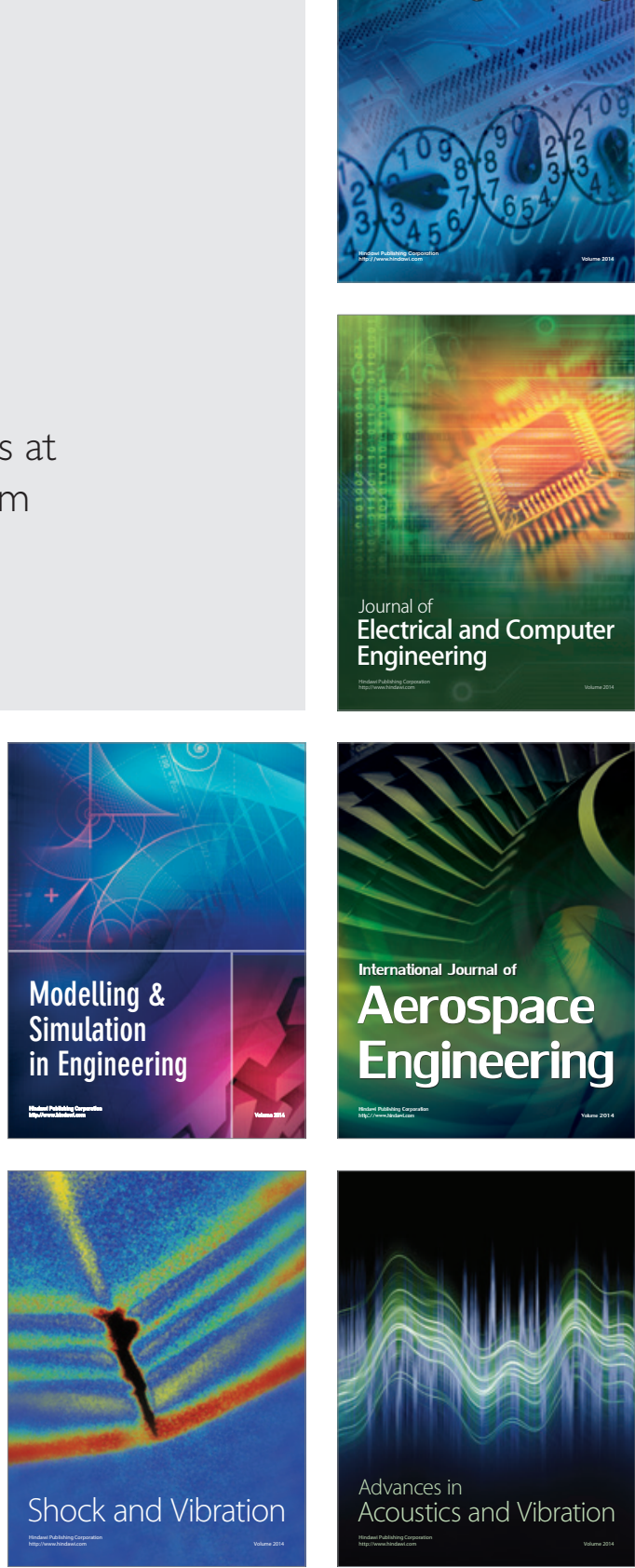